\title{
La reinvención del libro de bolsillo en España en la era del e-book (2000-2016)
}

The pocket book is reinvented in Spain in the era of the E-book (2000-2016)

\author{
María Olivera Zaldua (1), Juan Miguel Sánchez Vigil (1), Juan Carlos Marcos Recio (2)
}

(1) Facultad de Ciencias de la Documentación de UCM, C/Stma Trinidad 37 28010, molivera@ucm.es, jmvigil@ucm.es (2) Facultad de Ciencias de la Información de la UCM, Av. Complutense s/n 28040 jmarcos@ucm.es

\begin{abstract}
Resumen
El libro de bolsillo ha sido y es el preferido por un amplio sector de la sociedad entre la oferta editorial, debido a sus características definitorias: pequeño formato, diversidad de contenido y bajo precio. A comienzos del siglo XXI la irrupción del libro electrónico propició el debate sobre su futuro y algunos sectores vaticinaron su desaparición en pocos años. Es objeto de este artículo analizar la evolución del libro de bolsillo dentro del sector editorial en el periodo comprendido entre los años 2000 y 2016, teniendo en cuenta el desarrollo paralelo del libro digital y la competencia que éste supuso en cuanto a su producción y a los precios por suscripción y descarga. Como resultado, basándonos en los datos de creación, producción y facturación, se observa que el modelo bolsillo ha mantenido su espacio en cantidad y calidad a pesar de las crisis económicas y del crecimiento del libro electrónico.
\end{abstract}

Palabras clave: Libro de bolsillo. Edición digital. Documentación editorial. Historia de la edición..

\section{Introducción}

El libro de bolsillo es el de mayor predicamento en el mercado editorial debido a sus características específicas: pequeño formato, diversidad de contenidos y bajo precio. Ha sido definido por numerosos autores y con diferentes visiones. Martínez de Sousa (2004: 585) lo presenta como aquel que "con propósito de mayor difusión de su contenido se edita en tamaño reducido, en grandes tiradas y a precio asequible". Borras Perelló (2015: 296) lo define como "el de pequeño formato $(18 \times 11 \mathrm{~cm})$ en blanco y negro, generalmente en rústica, de gran difusión y costo relativamente bajo".

En cuanto al libro electrónico, Valentín Ruiz (2014: 49) lo presenta como "Obra científica, literaria o de cualquier otra índole con extensión suficiente para formar volumen en formato adecuado para ser leída en un dispositivo electrónico o en la pantalla de una ordenador". En relación al bolsillo, se alude al contenido y formato, pero no a su precio, que se presupone bajo al no ser

\begin{abstract}
Pocket books have been and are still being purchased in large amounts from the general book offer by an important sector of society, due to their leading characteristics: their small format, diversified contents and low price. At the beginning of the 21st century, the emergence of the E-book propitiated a great deal of debate on the future of book forms and several sectors predicted the disappearance of the pocket book in just a few years' time. The aim of this article is to analyze the evolution of pocket books within the publishing sector between 2000 and 2016, bearing in mind the simultaneous development of digital books and the competition they represent in regard to their production and the subscription and downloading costs. Based on data pertaining to creation, production and invoicing, we can conclude that pocket books have held their ground in terms of quantity and quality despite the financial crisis and the growing popularity of the E-book.
\end{abstract}

Keywords: Pocket books. Digital publishing. Editorial documentation. History of publishing.

necesaria la inversión en papel, almacenamiento y distribución, de ahí que su desarrollo en la primera década del siglo XXI hiciera pensar a los expertos que haría competencia al bolsillo.

Es objeto de este artículo analizar la evolución del libro de bolsillo en el periodo comprendido entre los años 2000 y 2016, en pleno desarrollo del libro electrónico. Los objetivos específicos son conocer la producción global, las editoriales y colecciones destacadas, así como establecer una comparativa con la producción de libros digitales en general con el fin de conocer el impacto de este modelo editorial.

La metodología seguida ha sido cuantitativa y cualitativa, partiendo de la recopilación y análisis de datos sobre la producción editorial del libro de bolsillo a partir de la fuentes institucionales, su representación mediante tablas y gráficos explicativos, la elaboración de un listado de las principales colecciones de bolsillo editadas entre 2000 y 2016 (anexo), la consulta de las páginas web de las editoriales, la búsqueda de bibliografía y hemerografía sobre el desarrollo y producción de 
libros electrónicos, y por último la comparativa entre ambos modelos.

En lo que se refiere al estado de la cuestión y a las fuentes sobre el desarrollo, producción y comercialización, han sido fundamentales las instituciones que coordinan y gestionan la actividad editorial, en especial los informes sobre el Comercio Interior del Libro de la Federación del Gremio de Editores de España, la Panorámica de la edición de libros del Ministerio de Cultura y otros datos oficiales de este mismo Ministerio. En cuanto a los datos históricos de los últimos años se ha consultado la reciente publicación La cultura en el bolsillo. Historia del libro de bolsillo en España (Sánchez, Gonzalo, Reyes, Olivera, 2018), y para la valoración de sus características El libro y la edición (Borras, 2015).

Sobre las características y producción del libro electrónico se han publicado numerosas monografías, entre las que citaremos como referente El libro digital y la www de Codina (2000), quien lo define como: "Publicación digital no periódica, es decir que se completa en un solo volumen o en un número predeterminado de volúmenes, y que puede contener cualquier morfología de la información". De gran interés es la tesis doctoral de Valentín Ruiz (2014) titulada El libro electrónico en las bibliotecas españolas. Evolución, gestión y análisis de contenidos y dispositivos de lectura y el libro Gutenberg 2.0. La revolución de os libros electrónicos de Cordón, Gómez y Alonso (2011). Se han consultado además varios artículos específicos sobre el desarrollo del libro de bolsillo en España, obra de Nallvalue (2005), Vázquez Reina (2009), Paula (2010) y Camero (2012).

\section{El libro de bolsillo en la era del e-book}

La producción de libros electrónicos o digitales comenzó a mediados de la década de los ochenta del siglo XX con la edición de diccionarios y enciclopedias, cuyo antecedente se encuentra en el Index de la Enciclopedia Espasa elaborado en 1984 (Sánchez Vigil, 2004). Durante la última década del siglo $X X$ la actividad editorial tuvo dos eventos de gran interés en España: los congresos de Granada (1994) y Benalmádena, Málaga (1998), en los que se analizaron los problemas del sector y se acordó como objetivo el desarrollo del libro electrónico. Siguiendo un orden cronológico expondremos algunos referentes de ese periodo, partiendo de 1991 cuando Plaza y Janés presentó la colección Jet con el objetivo de recuperar bestsellers de autores contemporáneos. Un año después, en 1992, Alfaguara sacó la colección Alfaguara bolsillo, diseñada por Miriam López y Jesús Sanz, aprovechando los títulos más vendidos en formato trade. Tusquets ideó la colección Fábula en 1993 con textos de autores universales: Umberto Eco, Emil Cioran, Albert Camus o John Updike, y en 1994 Akal editó Básica de Bolsillo con variedad de contenidos y autores. También en 1994 Ediciones B creó Vib, dedicada a bestsellers de autores extranjeros, y la mítica colección Austral fue reestructurada por Espasa. En 1995 Alianza inventó Alianza Cien, cuyo nombre respondía al precio (100 pesetas por ejemplar), con un formato de $10 \times 14 \mathrm{~cm}, 64$ páginas y el objetivo de: "Poner al alcance de todos las mejores obras de la literatura y pensamiento universales en condiciones óptimas de calidad y precio". Alianza lanzó otro modelo en 1997 que tituló Libros de Bolsillo, al que respondió Planeta con Booket, cuyo catálogo se confeccionó conlos fondos de más de cincuenta editoriales del Grupo.

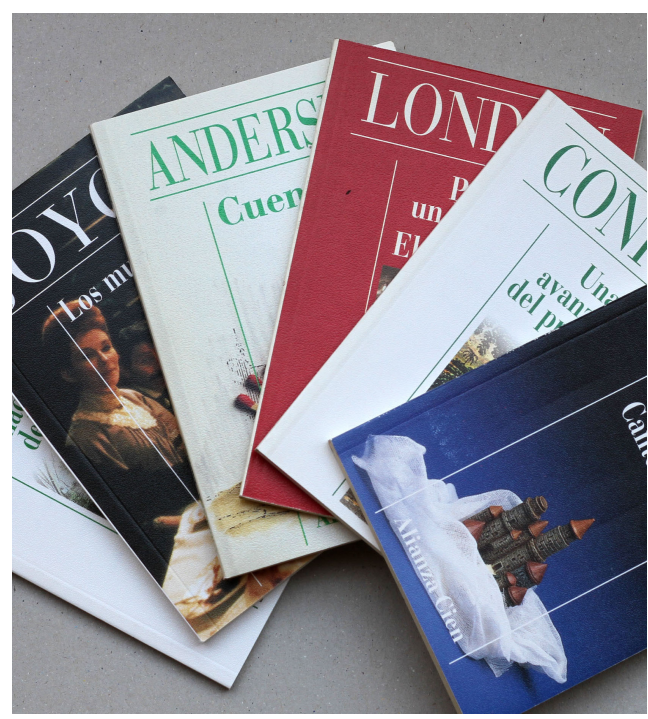

Figura 1. Alianza 100, 1995

\subsection{Nuevas colecciones del siglo XXI}

En el año 2000 se celebró el Congreso Nacional de Editores en Bilbao bajo el lema "Editar para leer", evento en el que el libro de bolsillo tuvo su espacio como preludio de las nuevas colecciones del siglo XXI. Una de las primeras fue Titania (2001) de la editorial Urano, dedicada a la novela romántica y dividida en series. Península lanzó nueva colección en 2001 sin nombre específico, diseñada por Andry Noguerón. Salamandra creó en 2002 Letras de Bolsillo con un diseño en colores según los contenidos siguiendo la pauta tradicional de Penguin y Austral. En febrero de 2002 se presentó el proyecto Quinteto con el objetivo de editar libros de calidad para el gran público y compuesto por cinco editoriales: Anagrama, Edhasa, Salamandra, Tusquets y Grup 62 con dos 
empresas, Península y Muchnik. La distribución la realizó Comercial Planeta, que puso en el mercado cien mil ejemplares en un breve periodo de tiempo, ya que se lanzaron diez títulos con una tirada de diez mil ejemplares. Con este modelo colaborativo se dio un importante impulso al libro de bolsillo, tanto cultural como económico.

A partir de febrero de 2004, Ediciones B recuperó muchos de los títulos de la antigua Bruguera para incluirlos en Byblos, colección dirigida por Santiago del Rey y diseñada por Ignacio Ballesteros (Mora, 2004, 2005). Ese mismo año se creó la colección Bolsillo de La Esfera de los Libros, con el objetivo de llegar a los lectores más jóvenes (Rodríguez, 2004). Diamante, de Edhasa, salióel 1 de octubre de 2006 para conmemorar el sesenta aniversario de la empresa con títulos seleccionados del fondo, entre ellos La montaña mágica y Muerte en Venecia de Thomas Mann, Los hechos del Rey Arturo de John Steinbeck, Memorias de Adriano de Marguerite Yourcenar, y La peste de Albert Camus.

Otro modelo colaborativo fue Books 4 Pocket, constituido en 2007 por tres empresas para repartir la inversión: Urano, Almuzara y Obelisco. La producción fue de cuatro a seis novedades mensuales en formato $12 \times 19 \mathrm{~cm}$. El primer número fue La historiadora de Elizabeth Kistova (serie Narrativa). Otro grupo de interés fue Puzzle, compuesto por una docena de sellos pequeños: Urano, Roca, Titania, Umbriel, El Jueves, La Factoría de Ideas, Entrelibros, Nowtilus, Kailas, Robin Book, Via Magna e Inédita. Tusquets pondría en el mercado a partir de 2007 un centenar de obras en formato $12,5 \times 18 \mathrm{~cm}$, resumiendo el contenido en la contra y con un breve apunte biográfico del autor. Los siete primeros títulos se reservaron para las novelas de Almudena Grandes, rescatadas del formato trade, entre ellas: Los aires difíciles, Atlas de geografía humana o Malena es un nombre de tango.

Las editoriales clásicas como Cátedra lanzaron nuevas colecciones de literatura como Mil Letras (2008-2009), Clásicos Linceo (2009-2014), Letras Populares (2011) y Cátedra Base (2013), y nacieron otras nuevas como La Factoría de Ideas que creó en 2008 Bolsillo de Ideas, con bestsellers de crimen, misterio, terror y ciencia ficción.

En 2009 el mercado de bolsillo se lo disputaban cinco colecciones: DeBolsillo de Random House, con casi un $40 \%$ de las ventas, Punto de Lectura de Suma de Letras (Santillana), Alianza de Anaya, Booket de Planeta, y Byblos del Grupo Zeta (Rodríguez, 2009). Planeta amplió la oferta con el lanzamiento de la Biblioteca de Bolsillo, y todo tipo de contenidos: literatura, ensayo, arte, ciencia, economía, etc.
Ediciones B del Grupo Z importó de Holanda el modelo Librino, presentado en noviembre de 2010 , con formatos $8 \times 12 \mathrm{~cm}$ y 145 gramos de peso gracias al papel biblia empleado en la impresión. Encuadernados en tapa dura e impresos en horizontal, imitan la forma de e-book. Las tiradas medias son de 12.000 a 20.000 ejemplares, con precios incluso más bajos que los contenidos digitales. Los primeros títulos en lanzarse fueron bestsellers de diferentes géneros: Novela histórica (Africanus de Santiago Posteguillo), Novela romántica (Postada: te quiero de CeceliaAhem), Thriller (El Psicoanalista de John Katzenbach), Terror (Entrevista con el vampiro de Anne Rice) y Novela negra (El invierno en Madrid de C. J. Sansom).

En 2011 salieron B de Bolsillo (Ediciones B del Grupo Z) y Gigamesh Bolsillo, con la serie Canción de hielo y fuego de George R. R. Martin, cuyo primer título fue el popular Juego de tronos. El diseño de las cubiertas de esta serie fue de Enrique Corominas. RBA apostó por Agatha Christie y la Serie Negra, aprovechando el 125 aniversario del nacimiento de la autora, colección formada por 43 títulos en formato $14 \times 21 \mathrm{~cm}$.

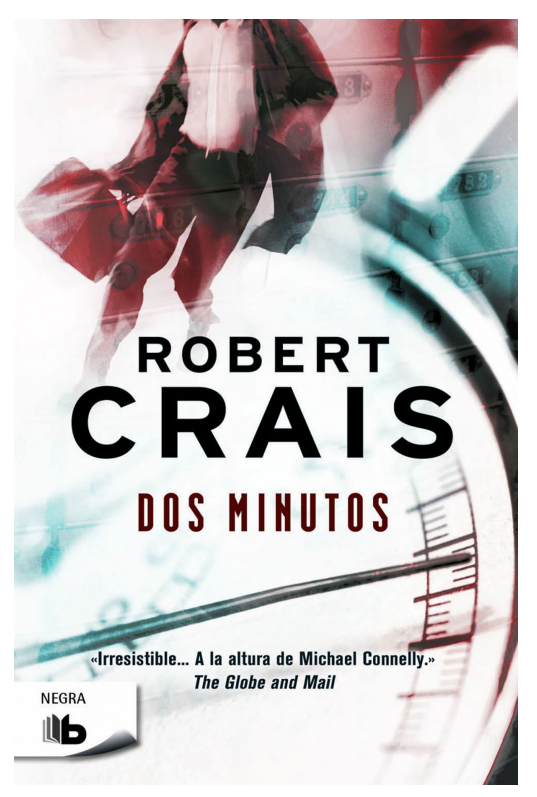

Figura 2. B de bolsillo. Ediciones B, Grupo Z, 2015

\subsection{Colecciones de las grandes editorales}

Los grandes grupos editoriales, conscientes de la posibilidad de explotación de sus catálogos a través del bolsillo, crearon a partir del año 2000 nuevas colecciones mediante las que aumentaron la oferta de calidad a precios competitivos. Alianza, Ediciones B, Planeta y Penguin Random House pusieron en marcha colecciones y relanzaron las clásicas. 


\subsubsection{Alianza: Libros de Bolsillo}

La colección, basada en la tradicional del mismo título, fue relanzada en 1997 con formato $11,5 \times 17,5 \mathrm{~cm}$. Los contenidos fueron abiertos, con traducciones, prólogos y notas sobre literatura, ensayo, biografía e incluso con bibliotecas de autores. Se publicaron entre 150 y 170 títulos por año, clásicos y contemporáneos, muchos recuperados del catálogo tradicional. El diseño de cubierta fue responsabilidad de Ángel Uriarte y Rafael Sañudo, manteniendo el estilo anterior en cuanto a las imágenes e incluyendo además fotografías. Se presentaron distintas series: Biblioteca de Autor; Literatura; Filosofía, Historia y Humanidades; Juvenil; Fantasía y Terror; Ciencia; Ciencias Sociales y Clásicos de Grecia y Roma. Como complemento a las distintas series se lanzaron otras de contenidos especializados como $13 / 20$, alusiva a su formato $(13 \times 20 \mathrm{~cm})$.

\subsubsection{Ediciones B: $Z$ Bolsillo y $B$ de Bolsillo}

La colección $Z$ Bolsillo de Ediciones $B$ surgió en 2005 , en rústica y tapa dura, con varias temáticas: Novela histórica, Romántica, Negra y Espiritualidad. Con formato $12,5 \times 20 \mathrm{~cm}$ se publicó una media de 150 obras al año, recuperadas en dos terceras partes de los bestsellers de la editorial. A partir de 2011 compartió espacio en la editorial con $B$ de Bolsillo, inicial de Bruguera. Z Bolsillo fue sustituida por B de Bolsillo en 2011 (11x17 $\mathrm{cm}$ ), en una renovación que vino a elevar aún más la calidad de las publicaciones con elegantes cubiertas ilustradas. Se estructura por series: Histórica, Romántica, Ficción, No Ficción, Inédito y Negra. Además publica con la marca Nova una colección de Ciencia Ficción en bolsillo y trade.

\subsubsection{Penguin Random House: DeBolsillo}

Bertelsmann, a través de Random House, creó junto a Planeta al $50 \%$ la empresa Nuevas Ediciones de Bolsillo, dirigida por Osmán Vega, lanzando la colección DeBolsillo a finales de 1999 con dos vías de alimentación, la primera desde Berstelmann con obras de Plaza y Janés, Debate y Lumen, y la segunda desde Planeta con libros de Bestsalia, Espasa, Destino, Ediciones del Bronce, Ariel, Crítica, Seix Barral, Temas de Hoy, Martínez Roca y Deusto.El primer y casi único lanzamiento fue de 32 títulos en marzo del 2000 con una tirada global de 600.000 mil ejemplares. El proyecto duró tan solo unos meses hasta abril de 2001. La gestión de DeBolsillo pasó a Random House (Bertelsman) con una media de 70 títulos al objeto de "Conseguir que el libro de formato pequeño ocupe el lugar que le corresponde en las librerías y en los hogares". Los fondos procedieron de Lumen, Debate, Mondadori y Grijalbo, con obras de Ken Follet, Javier Marías, Franz Kafka o
John Grisham. Penguin Random House apostó por crear nuevas colecciones impresas como Penguin Clásicos (mayo de 2005), con obras del ámbito hispano y universal a precios entre 7 y 14 euros de autores como Cervantes, Clarín, Quevedo, Shakespeare, Daniel Defoe, Mary Shelley o Jane Austen. Su propósito, según la editora María Casas, era: "Beber de todas las fuentes conocidas y por descubrir" (Oliver, 2015).

\subsubsection{Planeta: Booket y Austral}

Booket se lanzó en dos etapas, la primera en 1997 cuando la editorial Summa ideó la marca, compuesta por los términos booky pocket (CastiIlo, 1997). Planeta firmó un acuerdo con Bertelsmann a finales de 1999 para lanzar DeBolsillo, pero el proyecto no funcionó y tras la ruptura comenzó una segunda etapa con el relanzamiento en 2001, dirigida por Santos Palazzi, quien la presentó como: "La estructura mínima necesaria para relanzar al mercado hispanoamericano novelas tanto de autores nacionales como extranjeros, con el objetivo de hacer llegar al lector los títulos que se ajustan a su perfil" (Domenech, 2001). El formato fue estándar $(12,5 \times 19 \mathrm{~cm})$ y se estructuró en series. La fuente fue el amplísimo catálogo del Grupo Planeta. La tirada establecida fue de 20.000 a 40.000 ejemplares, y en una década, entre 2001 y 2012, se vendieron 35 millones de ejemplares, con más de 2.000 títulos de 700 autores.

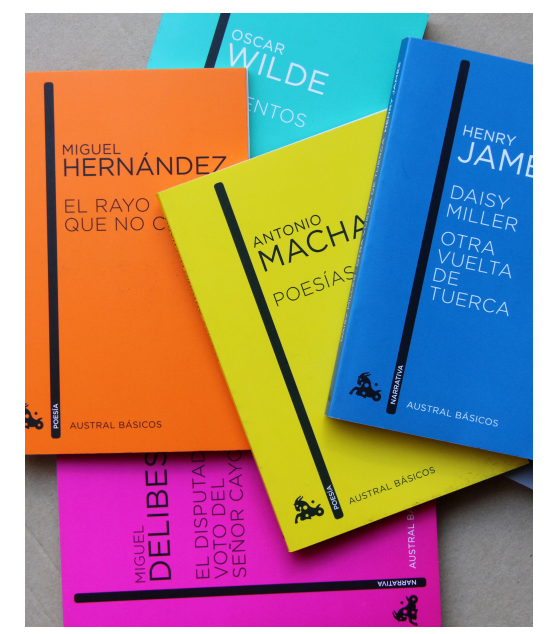

Figura 3. Austral Básicos, 2013

El proyecto Austral, surgido en 1937, tuvo su primera variación en 1975 al crear Selecciones Austral, formada por un conjunto de obras recuperadas del catálogo, más otras de contemporáneos. En 1987 tuvo un segundo relanzamiento con Austral Nueva, y después se modificarían los formatos y su presentación para llevar a cabo diseños muy 
elaborados como Austral Summa (1997), con tapa dura y papel especial, o Gran Austral (2006), para culminar con Austral Edición Especial (2005), diseñada por Tasmanias, de nuevo en el formato tradicional del bolsillo $12,5 \times 20 \mathrm{~cm}$, tapa dura e ilustración en cubierta. En septiembre de 2008 se presentó otra versión con diseño de Tasmanias, Joaquín Gallego, Mas!gráfica, Promorfa y Cristina Vergara. Gran Austral salió en enero de 2006 con el objetivo de difundir títulos imprescindibles en todas las áreas del pensamiento y el conocimiento, y en 2006 la aportación de Austral fue reconocida con el Premio Nacional del Ministerio de Cultura al Fomento de la Lectura. En 2010 la colección fue relanzada de nuevo con sello propio, lo que vino a significar un importante cambio al dar autonomía a una colección que pasaba de tal a independiente.

\subsubsection{Suma de Letras: Punto de Lectura}

Punto de Lectura fue creada en 2000 por el sello Suma de Letras de Ediciones B y Santillana, con diseño de Ignacio Ballesteros. El Grupo Santillana aportó fondos de Alfaguara, Taurus y Aguilar, mientras que Ediciones $B$ añadió los suyos y los de las filiales americanas. Se recuperaron obras de los catálogos de Alfaguara, Taurus, El País Aguilar y Alba. En una década la colección sumó un millar de títulos y se vendieron más de veinte millones de ejemplares. El formato fue de $11 \times 17,5 \mathrm{~cm}$, modificado después a $12 \times 19,5$. Santillana Ediciones Generales (Grupo Prisa) compró a Ediciones B (Grupo Zeta) en febrero de 2004 su participación del 50\% en Suma de Letras. En abril de 2005, el sello se amplió a formatos mayores y a la literatura comercial, especialmente a la novela de género: histórica, romántica, policial, fantástica, etc. (Santillana, 2005). Una década más tarde, en 2014, Suma de Letras fue vendida por Prisa a Penguin Random House.

\section{Producción de libros de bolsillo y libros electrónicos}

A finales del siglo XX, en 1997, la producción de bolsillo supuso el $9,5 \%$ del total de los libros editados en España, sumando 5.409 títulos y más de treinta millones de ejemplares vendidos. Hasta el año 2000 la cifra no solo se mantuvo sino que aumentó considerablemente para caer después en un paulatino descenso y mantener después un equilibrio entre 2004 y 2016. El libro electrónico comenzó a comercializarse en los años noventa, si bien las editoriales fueron reticentes a la inversión debido a la piratería y a las inciertas expectativas de mercado.

\subsection{Producción de libros de bolsillo}

Entre 1997 y 2000 los títulos publicados fueron en progresivo aumento hasta superar la cifra de los 6.000, si bien el descenso fue considerable hasta 2007 en que fueron recuperando paulatinamente la media anterior. La producción se mantuvo en esa cifra hasta el 2010 , y desde entonces al 2016 bajó un 30\% (Tabla 1 y Figura 4).

\begin{tabular}{|c|c|c|c|c|}
\hline Año & $\begin{array}{l}\text { Títulos } \\
\text { totales }\end{array}$ & $\begin{array}{l}\text { Titulos } \\
\text { bolsillo }\end{array}$ & $\begin{array}{c}\% \\
\text { bolsillo }\end{array}$ & $\begin{array}{c}\text { Ejemplares } \\
\text { vendidos }\end{array}$ \\
\hline 1997 & 48.214 & 5.409 & 11,21 & 31.055 .021 \\
\hline 1998 & 52.493 & 4.503 & 8,57 & 19.466 .623 \\
\hline 1999 & 57.849 & 6.233 & 10,77 & 33.506 .691 \\
\hline 2000 & 58.893 & 6.134 & 10,41 & 31.405 .994 \\
\hline 2001 & 60.267 & 3.956 & 6,56 & 32.000 .718 \\
\hline 2002 & 62.337 & 3.610 & 5,79 & 30.300 .000 \\
\hline 2003 & 65.824 & 4.846 & 7,36 & 30.297 .527 \\
\hline 2004 & 67.822 & 5.031 & 7,41 & 37.261 .117 \\
\hline 2005 & 69.598 & 5.378 & 7,72 & 43.353 .034 \\
\hline 2006 & 68.930 & 5.232 & 7,59 & 38.212 .871 \\
\hline 2007 & 70.520 & 6.392 & 9,06 & 37.333 .794 \\
\hline 2008 & 72.982 & 6.608 & 9,05 & 37.919 .103 \\
\hline 2009 & 76.213 & 6.425 & 8,43 & 35.783 .533 \\
\hline 2010 & 79.839 & 6.001 & 7,51 & 32.631 .000 \\
\hline 2011 & 83.258 & 5.376 & 6,45 & 35.717 .615 \\
\hline 2012 & 79.175 & 4.806 & 6,07 & 30.257 .000 \\
\hline 2013 & 76.434 & 4.099 & 5,36 & 21.756 .000 \\
\hline 2014 & 78.508 & 3.615 & 4,60 & 19.219 .000 \\
\hline 2015 & 80.181 & 4.211 & 5,25 & 17.127 .000 \\
\hline 2016 & 81.496 & 4.471 & 5,48 & 19.141 .000 \\
\hline Total & 1.390 .833 & 186.865 & ----- & 613.744 .641 \\
\hline
\end{tabular}

Tabla I. Libro de bolsillo: Títulos publicados y ejemplares vendidos, 1997-2016 (Federación de Gremios de Editores de España, 2017)

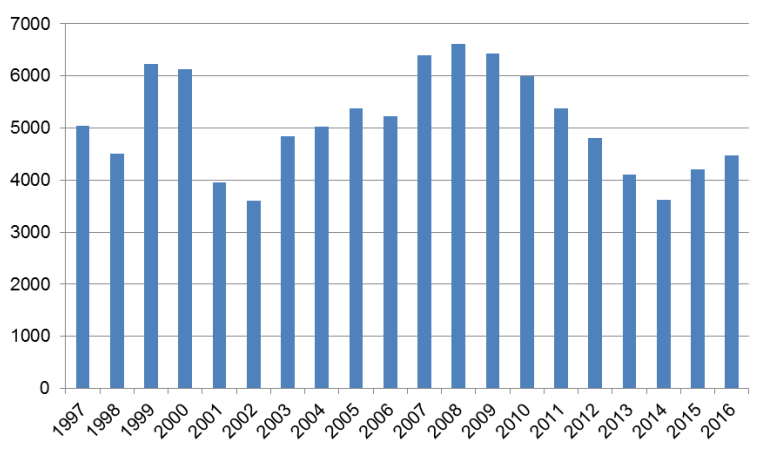

Figura 4. Libro de bolsillo: Títulos publicados, 1997-2016 (Federación de Gremios de Editores de España, 2017) 
En 2005 Barcelona se situó a la cabeza de la edición del libro de bolsillo, con el $61 \%$ de los títulos, mientras que en Madrid se produjo sólo el 38,2\%. Ese año se celebró en la capital el Primer Seminario Internacional del Libro de Bolsillo organizado por Santillana con el objetivo de analizar la situación y perspectiva del modelo. Participaron países europeos y americanos (Alemania, España, Francia, Italia, Reino Unido, Argentina, México, Colombia y Estados Unidos), y los resultados del evento fueron positivos en cuanto al crecimiento. Pere Duck e Ignacio García-Barredo concluyeron: "El libro de bolsillo se irá desproletarizando y convirtiéndose en un libro para las clases medias" (Ruiz Mantilla, 2005: 17).

Entre 2010 y 2014 se produjo un fuerte descenso en el número de títulos coincidiendo con la crisis económica y en consecuencia en la producción, pasando de 6.000 a 4.211, y de 32 millones de euros a tan solo 17. Juan Díaz, director de la colección DeBolsillo (Random House), declaró en una entrevista que el bolsillo no crecería más en España a partir de junio de 2012, debido a que la crisis había afectado a los puntos de venta y porque la compra impulsiva de libro barato se había reducido considerablemente (Mora y Geli, 2012: 38). En el mismo artículo Luis González (Fundación Germán Sánchez Ruipérez) afirmó que el bolsillo tenía "la batalla perdida frente al libro digital" y Fernando Valverde (Confederación Española del Gremio y Asociaciones de Libreros) matizó que: "En España la fortuna del libro de bolsillo nunca fue tan buena como en otros países". Para Ciompi (2014: 61) el libro digital fue una de las causas del descenso de su producción:

El libro de bolsillo es el territorio privilegiado de los grandes lectores [...] Y son precisamente éstos los que han hecho la fortuna del libro de bolsillo en otros países de nuestro entorno. Es España no, ya que no contamos con el número de lectores habituales suficientes para sostener adecuadamente la edición de bolsillo, y el retraimiento en el consumo y la irrupción del digital no han hecho más que acentuar el problema.

A partir de 2015 se produjo un ligero aumento que parecía responder a la salida de la crisis, con casi un punto porcentual sobre los títulos totales editados, alcanzando el $5,48 \%$ y que supuso más de 19 millones de ejemplares vendidos.

\subsection{Producción del libro electrónico}

La producción del libro electrónico tiene dos etapas diferenciadas en la primera década del siglo XXI. Entre 2000 y 2005 los títulos aumentaron progresivamente y a partir de 2007 lo hicieron considerablemente. El término digital se ha empleado como sinónimo de electrónico por los profesionales del sector editorial y los teóricos elucubraban sobre su impacto, sobre todo en el libro de bolsillo. El Ministerio de Cultura incluyó los libros electrónicos dentro de un apartado denominado Multimedia y otros soportes en la Panorámica de la edición publicada entre 2000 y 2005. La mayoría de los títulos editados en ese lustro se presentaban todavía en CD-Rom y en Archivos para Internet, y no para dispositivos electrónicos de lectura (e-reader), con una cifra reducida de títulos en relación a la producción total (Tabla II).

\begin{tabular}{lrrrrrrr}
\hline Año & 2000 & 2001 & 2002 & 2003 & 2004 & 2005 & 2006 \\
\hline ISBNs & 58.893 & 60.267 & 62.337 & 65.824 & 67.822 & 69.598 & 68.930 \\
\hline Libros el. & 2.011 & 3.198 & 3.317 & 3.912 & 4.478 & 4.890 & 3.896 \\
$\%$ & 3,14 & 5,3 & 5,32 & 5,97 & 6,6 & 7,02 & 5,56 \\
\hline$C D$ & 67 & 68,6 & 74,7 & 72,7 & 82,4 & 77,8 & 71,9 \\
\hline DVD & 8,8 & 3,7 & 12,1 & 25,4 & 26,5 & 35,7 & 38,8 \\
\hline On-line & 25,3 & 25 & 17 & 23,5 & 20,6 & 19,9 & 22 \\
\hline Videos & 39 & 34,8 & 34 & 24,6 & 31,2 & 16,4 & 4,5 \\
\hline Casetes & 37,9 & 38,2 & 32,9 & 24,9 & 22,4 & 13,5 & 6,5 \\
\hline Otros & 0,5 & 2,5 & 7 & 4,4 & 11,8 & 13,3 & 7,7 \\
\hline
\end{tabular}

Tabla II. Producción de libros electrónicos 2000-2006

(Federación de Gremios de Editores de España, 2017)

El crecimiento real surgió a partir de 2007 con 7.765 títulos, el doble del año anterior. Desde entonces hasta 2016, en que se publicaron 25.237, la subida ha sido del $325 \%$. Ahora bien, cabe preguntarse si realmente las cifras responden a las expectativas, toda vez que el sector editorial vaticinaba la desaparición de gran parte de los libros en papel en un periodo de tiempo breve.

\begin{tabular}{cccc}
\hline Año & ISBN totales & Libros electrónicos & $\%$ \\
\hline 2007 & 70.520 & 7.765 & 11,01 \\
\hline 2008 & 72.982 & 8.062 & 11,04 \\
\hline 2009 & 76.213 & 12.514 & 16,41 \\
\hline 2010 & 79.839 & 18.221 & 22,82 \\
\hline 2011 & 83.258 & 23.794 & 28,57 \\
\hline 2012 & 79.175 & 24.381 & 30,79 \\
\hline 2013 & 76.434 & 23.070 & 30,18 \\
\hline 2014 & 78.508 & 22.310 & 28,41 \\
\hline 2015 & 80.181 & 22.279 & 27,78 \\
\hline 2016 & 81.496 & 25.237 & 30,96 \\
\hline Total & 778.606 & 187.633 & -------- \\
\hline
\end{tabular}

Tabla III. Producción de libros, 2007-2016 (Ministerio de Cultura, 2017)

El mayor crecimiento se dio entre 2009 y 2011, ya que la cantidad de títulos se dobló, pasando 
de 12.000 a cerca de 24.000 (Tabla III y Figura $5)$.

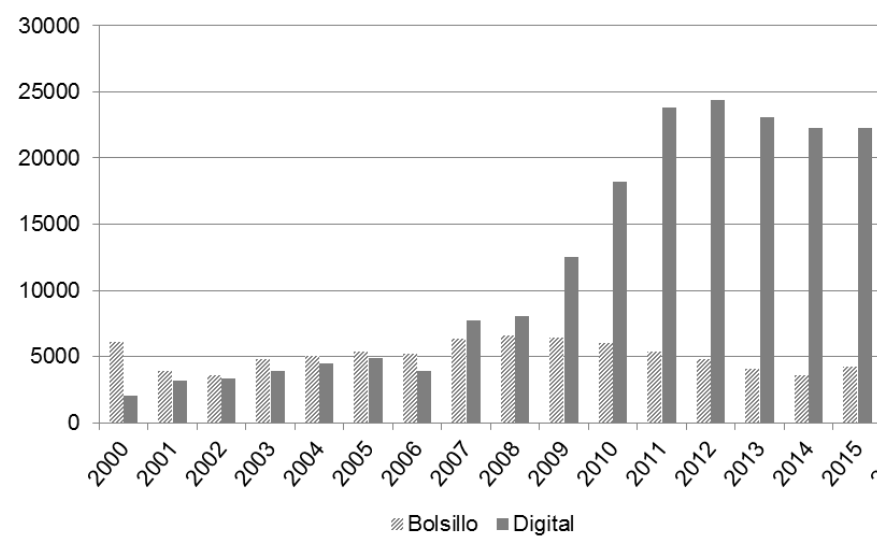

Figura 5. Comparativa de la producción de libros de bolsillo y libros digitales, 2000-2017 (Federación de Gremios de Editores de España, 2017)

Según el Comercio Interior del Libro en España, editado por la Federación de Gremios de Editores, en el año 2016 la edición en soportes distintos al papel la efectuaron 363 empresas de un total de 727 , es decir el $49,9 \%$, tres puntos más que en 2015 que fueron el 46,8\%. En 2016 el $87 \%$ de los títulos editados en formato digital se publicaron también en papel, y solo el $13 \%$ en formato digital, cifras similares a las de 2015. El número de editores y empresas que publicaron en formato digital entre 2007 y 2014 aumentó en un $100 \%$ con un estancamiento desde ese año hasta la actualidad.

\section{El factor precio: la facturación}

La competencia entre el libro de bolsillo y el digital se inició a comienzos del siglo XXI y tuvo en el precio, y en consecuencia en la rentabilidad, uno de los factores clave. El ahorro en papel, almacenamiento y distribución apuntaba al impacto en el bolsillo, que sin embargo no se produjo puesto que el precio de venta al público de los libros electrónicos en 2010 fue de 9 a 10 euros por ejemplar, dos puntos por encima del bolsillo. A finales de 1997 la empresa Tábula V realizó el estudio "Los españoles y los libros" en el que se indicaba que el $60 \%$ de los compradores se inclinaban preferentemente por el bolsillo, debido a su menor precio (Rodríguez, 2009), y en el año 2000 el precio medio por ejemplar era de 5,97 euros, pasando a 6,80 en 2008 , es decir un $11,30 \%$ superior. En 2009 la media subió hasta los 7 euros, y entre 2010 y 2014 otro 3,9\%, oscilando entre los 7,17 euros de 2010 y los 7,22 de 2014. Por tanto los precios han permitido y permiten competir al bolsillo con el libro digital.
La facturación global del libro de bolsillo en los últimos diecisiete años (Tabla IV, Figura 6), se aproxima a los 2.500 millones de euros, con una media anual de 146 millones entre 2000 y 2016. El descenso en los ingresos es significativo a partir de 2012 coincidiendo con la crisis económica, con una caída de más del $40 \%$ desde los 142 hasta los 90 millones de euros. Entre 2003 y 2008 subió un $35 \%$, pasando de 136 millones de euros a 196, y desde ese año hasta 2014 el descenso fue del $50 \%$, hasta situarse en una cifra algo inferior a la del año 2000. Es decir que se trata de un modelo inestable dentro del sector pero que se ha mantenido por encima de los cien millones de facturación.

\begin{tabular}{cccccc}
\hline Año & $\begin{array}{c}\text { Facturación } \\
\text { Total (1) }\end{array}$ & $\begin{array}{c}\text { Bolsillo (1) } \\
\text { Facturación }\end{array}$ & $\begin{array}{c}\text { Bolsillo } N^{\circ} \\
\text { Titulos }\end{array}$ & $\begin{array}{c}\text { Digital (2) } \\
\text { Facturación }\end{array}$ & $\begin{array}{c}\text { Digital } N^{\circ} \\
\text { Títulos }\end{array}$ \\
\hline 2000 & 2528,940 & 125,431 & 6.134 & $5,3 \%$ & 2.011 \\
\hline 2001 & 2606,070 & 140,712 & 3.956 & $4,4 \%$ & 3.198 \\
\hline 2002 & 2674,060 & 120,170 & 3.610 & $4,3 \%$ & 3.317 \\
\hline 2003 & 2792,061 & 136,592 & 4.846 & $5,2 \%$ & 3.912 \\
\hline 2004 & 2881,060 & 137,086 & 5.031 & $9,2 \%$ & 4.478 \\
\hline 2005 & 2933,023 & 155,280 & 5.378 & $9,8 \%$ & 4.890 \\
\hline 2006 & 3014,054 & 194,830 & 5.232 & $11,1 \%$ & 3.896 \\
\hline 2007 & 3123,170 & 190,190 & 6.392 & $10,5 \%$ & 7.765 \\
\hline 2008 & 3185,000 & 196,240 & 6.608 & $10,1 \%$ & 8.062 \\
\hline 2009 & 3109,580 & 180,460 & 6.425 & 51,259 & 12.514 \\
\hline 2010 & 2890,000 & 176,660 & 6.001 & 70,499 & 18.221 \\
\hline 2011 & 2772,340 & 185,130 & 5.376 & 72.576 & 23.794 \\
\hline 2012 & 2471,049 & 142,080 & 4.806 & 74,250 & 24.381 \\
\hline 2013 & 2181,097 & 117,280 & 4.099 & 80,266 & 23.070 \\
\hline 2014 & 2195,800 & 103,270 & 3.615 & 110,022 & 22.310 \\
\hline 2015 & 2257,070 & 94,570 & 4.211 & 115,442 & 22.279 \\
\hline 2016 & 2317,200 & 90,790 & 4.471 & 117,190 & 25.237 \\
\hline Total & $4.5931,574$ & $2.486,771$ & 86.191 & ---------- & 213.335 \\
\hline & & & & & \\
\hline 2006 & & & & \\
\hline
\end{tabular}

Tabla IV. Comparativa de la edición y facturación de bolsillo y digitales, 2000-2016 (Federación de Gremios de Editores de España, 2017)

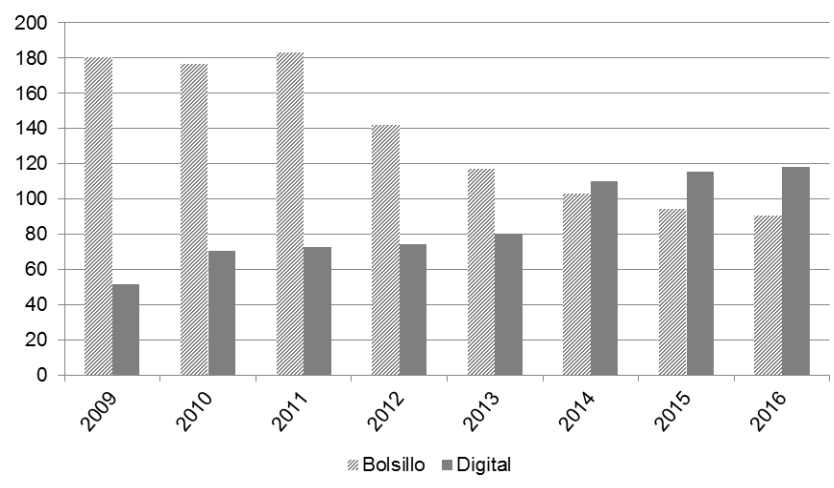

Figura 6. Comparativa de la facturación del libro de bolsillo y libros digitales, 2009-2017 (Federación de Gremios de Editores de España, 2017) 
En comparación con Europa, la facturación del libro de bolsillo a comienzos del siglo XXI era muy reducida, tan solo el $9 \%$ del total frente al $40 \%$ de Francia, Italia, Inglaterra o Alemania. Esta es una de las causas por las que las grandes editoriales apostaron por la adaptación al bolsillo de títulos ya publicados en formato trade (comercial), fundamentalmente los bestsellers, que se comercializaron a través de las nuevas colecciones, con ejemplo en Booket, DeBolsillo o Punto de Lectura.

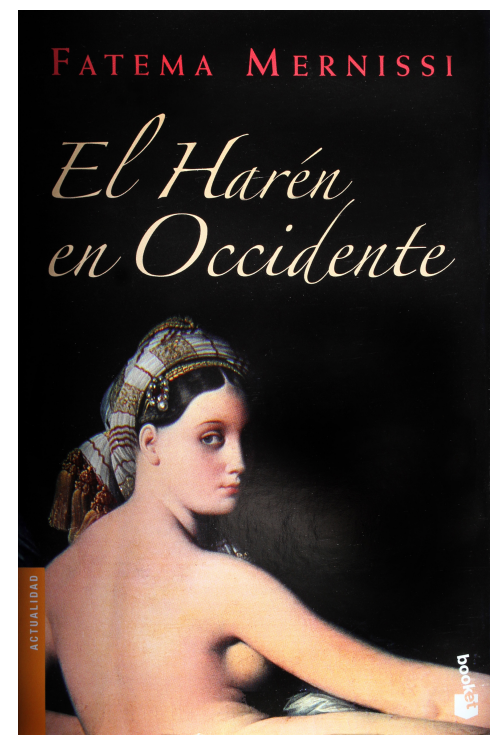

Figura 7. Booket, Planeta, 2013

En 2002 el sello que lideraba el mercado era DeBolsillo (Random House), con el $42 \%$ de la facturación, seguido de Punto de Lectura (Suma de Letras) con el25\% y de Alianza y Booket (Planeta) con el $8 \%$. La explotación de los fondos en formato trade fue una importante fuente de ingresos para las editoriales, en algunos casos muy significativa, como Destino con las obras de Miguel Delibes, que quintuplicó la venta en 2002, pasando de seiscientos mil ejemplares hasta tres millones, lo que nos indica la importancia del modelo bolsillo.

La facturación del libro digital se duplicó entre 2009 y 2014 , pasando de 50 a 110 millones de euros. En 2016 el número de ejemplares vendidos en formato electrónico disminuyó un 2,8\% (12,3 millones) con respecto a 2015 , si bien la facturación en 2016 aumentó un 1,5\% debido a la subida de un $4,4 \%$ del precio medio hasta los 9,5 euros por libro frente al 9,1 de 2015. Las materias Ciencias Sociales y Humanas, concretamente Derecho y Ciencias Económicas, son la de mayor facturación, y suponen el $44,4 \%$ del total facturado en formato digital. Junto al Texto no universitario $(22,4 \%)$ y la Literatura $(19,7 \%)$ suponen el $86,5 \%$ del total.

\section{Conclusiones}

La información facilitada por el sector editorial sobre el libro de bolsillo, tanto en los grandes grupos como en las medianas y pequeñas empresas, confirma que las colecciones no solo se han mantenido en los tres lustros del siglo XXI, sino que se han añadido nuevos proyectos. Los ejemplos son numerosos, como queda plasmado en el texto, con el paradigma en la colección Austral, que en 2018 ha lanzado tres nuevas series de contenidos clásicos: Austral Intrépida, Singular y Educación.

Del análisis realizado se observa como conclusión general que el libro de bolsillo ha mantenido una constante en cuanto a su producción y comercialización, si bien la crisis económica marcó un descenso del 20\% desde 2011 hasta 2016. Del mismo modo y aunque la producción del libro digital fue en constante aumento desde el año 2000, con un incremento extraordinario entre 2008 y 2010, a partir de 2011 sufrió un estancamiento que parece recuperarse en 2016, pero que debe ser confirmado en los próximos años.

Por otra parte, en el periodo estudiado, se constata que el considerable aumento de libros electrónicos solo ha afectado a la producción del libro de bolsillo. La hipótesis sobre la influencia o impacto de la edición digital en el bolsillo no se cumple, ya que éste modelo ha mantenido su nivel de producción como se observa en los ISBN registrados en los años que se estudian $(6,56 \%$ del total en 2001 y $5,48 \%$ en 2016), bajando solo un punto a pesar de la crisis económica. Por consiguiente podemos afirmar que este modelo ha sido básico para el mantenimiento del sector editorial en ese periodo.

En este sentido hemos de indicar que si en 2007 la producción anual era de 7.765 títulos y que su aumento ha sido constante hasta sumar algo más del $30 \%$ del total (25.237 títulos), al compararlo con las cifras del bolsillo se observa que afecta a otros modelos y no a éste. El factor precio tampoco parece ser determinante teniendo en cuenta que la media de las publicaciones digitales es similar al bolsillo, tema debatible si consideramos el menor coste de producción al eliminar la inversión en materia de producción, distribución y almacenamiento.

De todo lo anterior se concluye que frente al libro digital, cuya característica es la inmediata descarga de contenido a bajo precio, el modelo bolsillo en papel ha mantenido su mercado, siendo referente por calidad y también precio. 


\section{Anexo: Relación de colecciones de bolsillo (1990-2016)}

Alba Clásica (Alba, 1995)

Alfaguara Bolsillo (Alfaguara, 1992)

Alianza Cien (Alianza, 1995)

Austral (Planeta, 1997)

Austral Básicos (Planeta, 2013)

Austral Clasica (Planeta, 2010)

Austral Contemporánea (Planeta, 2010)

Austral Nueva (Espasa, 2005)

Austral Summa (Espasa, 1997)

$B$ de Bolsillo (Ediciones B, 2011)

Básica de Bolsillo (Akal, 1994)

Biblioteca de Bolsillo (Ediciones Crítica, 1999)

Biblioteca de Bolsillo (Planeta, 2009)

Bolsillo (La Esfera de los Libros, 2001)

Bolsillo de Ideas (Factoría de Ideas, 2008)

Bolsitemas (Temas de Hoy, 1995)

Booket (Planeta, 1997 y 2001)

Books 4 Pocket (Urano, Almuzara y Obelisco, 2007)

Byblos (Ediciones B, 2004)

Cátedra Base (Cátedra, 2013)

Clásicos Linceo (Cátedra, 2009-2014)

Clásicos RBA (RBA, 2013)

Claves (Maia ediciones, 2009)

Club Diógenes (Valdemar, 1994)

DeBolsillo (Bertelmann \& Planeta, 2000)

DeBolsillo (Penguin Random House, 2001)

Diamante (Edhasa, 2006)

Ediciones de Bolsillo (Península, 2001)

Embolsillo (Maeva, 2008)

Esfera de los Libros, La (1994)

Espasa Bolsillo (Espasa, 1998)

Fábula (Tusquets, 1993)

Fundamentos (Istmo, 1990)

Gran Austral (Espasa, 2006)

Jeto (Plaza y Janés, 1991)

Letras de Bolsillo (Salamandra, 2002)

Letras Populares (Cátedra, 2011)

Librino (Ediciones B, 2010)

Libros de Bolsillo (Alianza, 1997)

Maxi (Tusquets, 2007)

Mil Letras (Cátedra, 2008-2009)

Penguin Clásicos (Penguin, 2005)

Península Bolsillo (Península, 2001)

Punto de Lectura (Suma de Letras, 2000)

Puzzle (Urano y otras, 2007)

Quinteto (Anagrama y otras, 2002)

Serie Negra (RBA, 2014)

Titania (Urano, 2001)

Tusqutes Bolsillo (2007)

Vib (Ediciones B, 1994)

Z Bolsillo (Ediciones B, 2005)

\section{Referencias}

Borrás Perelló, L. (2015). El libro y la edición. Gijón: Trea.

Camero, F. (2012). Un paseo por el universo bolsillo // Mercurio. marzo 16-18.

Castilla, A. (1997). Planeta crea Booket, una editorial dedicada al libro de bolsillo. // El País, 22 de febrero de 1997. http://elpais.com/diario/1997/02/22/cultura (2015-11-20)

Ciompi, V. (2014). El libro de bolsillo // Delibros, enero 60-63.

Codina, L. (2000). El libro digital y la www. Madrid: Tauro.

Cordón García, J, A.; Gómez Díaz, R.; Alonso Arévalo, J. (2011). Gutenberg 2.0. La revolución de los libros electrónicos. Gijón: Trea.

Domenech, S. (2001). Planeta recupera Booket, división de libros de bolsillo, 200 títulos este año // La Razón, 5 abril 2001. www.antonioburgos.com/libros/.html (2015-11-25).
Federación de Gremios de Editores de España (2017). Comercio interior del libro en España 2016. Madrid: Federación de gremios de editores de España.42-43.

Martínez de Sousa, J. (1989). Diccionario de bibliología y ciencias afines. Gijón: Trea.

Ministerio de Cultura. Panorámica de la edición de libros: análisis sectorial del libro. Madrid: Ministerio de Cultura (2010-2017).

Ministerio de Cultura (2015). El libro de bolsillo en España, abril. Madrid: Ministerio de Cultura.

Ministerio de Cultura (2007). El libro de bolsillo en España, junio. Madrid: Ministerio de Cultura

Mora, R. (2005). Ediciones B mantendrá Byblos a 5 euros y sacará otro sello de bolsillo. // El País, 14 de julio de 2005. http://elpais.com/2005/07/14 (2015-11-15).

Mora, R. (2004). Byblos, nueva colección de bolsillo de Ediciones B. // El País, 10 de marzo de 2004. http://elpais.com/diario/2004/03/10/cultura (2015-11-25).

Mora, R.; Geli. C. (2012). El libro de bolsillo tiene un agujero. // El País, 14 de junio, 38.

Nallvalue (2005). Libros de bolsillo para impulsar la lectura // Eltiempo.com, 2005. www.eltiempo.com/archivo (201511-10).

Oliver, J. (2015). Penguin Clásicos desembarca en los primero títulos de literatura española. www.papelenblanco.com/editoriales/penguin-clasicos-desembarcacon-los-primeros-titulos-de-literatura-espanola (2015-1115).

Paula Juan, L. G. (2010). Reinventando el libro de bolsillo: 145 gramos que plantan cara al e-book. // elmundo.es, 24 de noviembre. www.elmundo.es/elmundo/2010/11/24 /cultura/1290607204.html (2015-11-7)

Rodríguez, E. (2004). La Esfera de los Libros apuesta por la edición de bolsillo. // El Mundo, 20 de mayo.

Rodríguez, J. C. (2009). Las editoriales se agarran al libro de bolsillo... a medias // El economista. http://ecodiario.eleconomista.es (2015-11-15).

Ruiz Mantilla, J. (2005). Los editores quieren inundar el mercado de bolsillo y los libreros se quejan por el espacio. // El País, 25 de mayo.http://elpais.com/diario/2005/05/25/cultura/1116972003 850215.html (201511-15).

Sánchez Vigil, J. M. (2004). Index: Proyecto para la recuperación electrónica de información en los contenidos de los Suplementos de la Enciclopedia Universal llustrada Espasa // Documentación de las Ciencias de la Información, 27, 279-287.

Sánchez Vigil, J. M.; Gonzalo Sánchez-Molero, J. L.; Reyes Gómez, F.; Olivera Zaldua, M. (2018). La cultura en el bolsillo: historia del libro de bolsillo en España. Gijón: Trea.

Santillana (2005).Santillana reactiva el sello Suma de Letras dedicado a la novela de género // El País, 19 de marzo. http://elpais.com/diario/2005/03/19 (2015-11-24).

Valentín Ruiz, F. J. (2014). El libro electrónico en las bibliotecas españolas. Evolución, gestión y análisis de contenidos y dispositivos de lectura. Madrid: Universidad Complutense de Madrid. Tesis Doctoral.

Vázquez-Reina, M. (2009). Libros de bolsillo, la mejor fórmula para leer el tiempo de crisis. // Consumer.es, 22 de febrero. www.consumer.es/web/es/educacion/cultura-yciencia/2009/02/22 (2015-11-24).

Enviado: 2018-03-26.

Aceptado: 2018-06-06. 
